\title{
Students academic and social concerns during COVID-19 pandemic
}

\author{
Azzah Al-Maskari ${ }^{1}$ - Thurayya Al-Riyami ${ }^{1}$ - Siraj K. Kunjumuhammed ${ }^{2}$
}

Received: 15 January 2021 / Accepted: 17 May 2021 / Published online: 30 June 2021

(C) The Author(s), under exclusive licence to Springer Science+Business Media, LLC, part of Springer Nature 2021

\begin{abstract}
Due to the COVID-19 pandemic, Higher Education Institutions (HEI) replaced regular face-to-face teaching with online teaching and learning. However, the shift caused several academic and social concerns for students, such as lack of academic support, lack of adequate resources to support online teaching, lack of socialization, stress, anxiety, and lack of motivation in attending classes. This research evaluates the impact of HEIs support, faculty support, and resources available on the academic and social concerns of students in HEIs during the pandemic. 11,114 students across the HEIs in Sultanate of Oman participated in an online national survey. Regression and factor analysis were used to verify the research model developed based on the literature review. Results showed that HEI support and faculty support significantly affect university students' academic and social concerns. Furthermore, resource availability was found to affect the academic concerns of students but not their social concerns. This research recommends strategies for HEIs and faculty to promote faculty-student interaction using both synchronous and asynchronous modes to reduce student concerns and motivate them to engage in online classes.
\end{abstract}

Keywords Academic concerns; social concerns - COVID-19 pandemic; support . Resources

Azzah Al-Maskari

almaskari.a@ict.edu.om

Thurayya Al-Riyami

thuraya_r@ict.edu.om

Siraj K. Kunjumuhammed

siraj@mcbs.edu.om

1 University of Technology and Applied Colleges- Ibra, Ibra, Oman

2 Modern College of Business and Sciences, Muscat, Oman 


\section{Introduction}

COVID-19 pandemic influenced all walks of life; the higher education sector is not an exception. Since WHO declared COVID-19 as a pandemic in March 2020, lockdown, social distancing, work from home, and online classes became part of life. Distance education replaced regular face-to-face classes; higher education institutions (HEI) rely heavily on a distance learning model to continue offering their programs. HEI invested heavily in IT infrastructure, trained staff and students, and moved their different activities online, including teaching and assessment. The shift, however, caused several concerns for students and staff. A few recent research have explored the challenges encountered by students during the pandemic (e.g., Mailizar et al., 2020; Aristovnik et al., 2020; Al-Salman \& Haider, 2021). However, all these studies suggested the need for further studies on students' responses towards online learning and their concerns (Basilaia \& Kvavadze, 2020; Mailizar et al., 2020; Basilaia \& Kvavadze, 2020).

Distance Education (DE) includes all study methods and all levels of education that do not enjoy direct and continuous supervision by teachers attending with their students in traditional classrooms. Still, the education process is subject to planning, organization, and directed by an educational institution and teachers" (Holmberg, 1977, p.9). DL experiments with synchronous or asynchronous environments using different devices such as mobile phones, tablets, or laptops. Participants interact with their teachers and share their ideas with colleagues remotely. It offers many benefits, for instance, flexibility. Besides, the course contents are accessible to students anytime. DE is not costly as it saves the costs of establishing new classrooms and saves electricity, water, and others (Ferriman, 2013). However, a low level of motivation, feelings of isolation, and loneliness are some of the challenges affecting DE's effectiveness (Hetsevich, 2017).

In the Sultanate of Oman, the Supreme Committee decided to suspend faceto-face classes and shift to online education on March 15, 2020. Accordingly, HEIs shifted teaching and learning online, modified their assessment scheme, and initiated measures to enhance their investments in IT. It allowed HEIs to continue their academic programs and maintain the health of their stakeholders. However, the shift posed significant challenges as it was not well planned. The challenges include lack of infrastructure and resources, teacher's inexperience in the virtual teaching mode, resources available for students, network connectivity issues. Indeed, the student's academic concerns and social concerns due to pandemic created a unique situation that was never a subject matter in the empirical research.

Against this background, this paper investigates students' academic and social concerns in the HEIs in the Sultanate of Oman. Specifically, this paper examines the role of HEI support, faculty support, and resources on the academic and social concerns of the students. 


\section{Literature review}

Academic concerns refer to learning difficulties, lack of attention from teachers, and increasing workload that have restricted students' ability to concentrate during online classes. Several authors around the world have researched students' academic concerns caused by COVID-19. For instance, Realyvásquez-Vargas et al. (2020) found that shifting to online learning affected students' academic performance and caused a lot of intellectual fatigue due to the increased workload. Also, the challenge includes a high risk of students dropping out of their courses (Cohen, 2017). The only way to overcome such a phenomenon is individualized monitoring, which is probably hard to be accomplished by all teachers (UNESCO, 2020). Besides, many students have not benefited from online learning since they have not received proper guidance from their teachers (Ali, 2020; Sullivan et al., 2018) and lose interest in attending classes online. Also, Al-Salman and Haider (2021) stated that the volume of assignments has negatively affected students' academic performance. In another study, Aristovnik et al. (2020) analyzed how students perceive the impact of the COVID-19 pandemic with a sample of 30,383 university students from 62 countries; their study revealed that students complained about the intensive workload that affected students' academic performance.

This paper defines social concerns as the outcome of student experiences, feelings of loneliness, fear of a pandemic, worries about health and the health of loved ones, and lack of communication with classmates and relatives. According to the UNESCO report (2020), the shift to a virtual mode of teaching-learning limited social contact and socialization routines, a central part of students' daily experience in HEIs. The report indicated that $75 \%$ of students in HEIs worldwide had experienced anxiety and unease due to the study suspension. In the same vein, Duraku and Hoxha (2020) found that a majority of students in HEIs reported moderate levels of stress $(65.4 \%)$, while more than one-quarter of students reported high levels of stress (26.9\%). Similarly, Almuraqab (2020), in his study in the UAE, found that more than half of respondents (58\%) agreed that distance learning made group collaboration among students less and very limited, which affected the ability to learn and interact with their classmates. Gillis and Krull (2020) observed that students experienced barriers to learning due to the pandemic, including distractions, increased anxiety, and feeling less motivated. Further, Aristovnik et al. (2020) found that students experienced boredom, anxiety, and frustration due to the adoption of particular hygienic behaviors that prevented them from performing simple daily practices such as shaking hands and getting in touch with their family members and friends.

\subsection{Factors that impact students' academic and social Concerns during online education}

The success of online classes depends on many factors. Empirical research univocally highlighted the critical role of faculty in shaping students' experience in online classes. For instance, Adnan and Anwar (2020), based on a study among 
126 undergraduates and postgraduate college students in different HEIs in Pakistan, found that students' academic performance is affected due to lack of face-to-face interaction with the instructors and delays in responding to students' inquiries. Bates and Khasawneh (2007) stated that frequent feedback from teachers improved students' academic performance and increased their motivation and engagement during online learning. Students learned more when their lecturers provided training on using the online learning system at the beginning of the course. In addition, Zhou et al. (2020) have found that most teachers in China are unfamiliar with synchronous and asynchronous online teaching tools and could not guide their students on using online platforms/or learning management systems. Hence, it is imperative that faculty knowledge, experience, and interaction during online classes significantly influence students' experiences in online classes.

Considering the challenges posed by the pandemic, Daniel (2020) observed that faculty should take advantage of asynchronous teaching to engage students and ease their concerns to juggle home and study demands. However, this is contrary to the expectation that faculty should continuously utilize synchronous platforms to engage in discussions and interactions with students. Drane et al. (2020) observed that students from more vulnerable backgrounds are likely to experience persistent disadvantage through a range of barriers, for instance, long-term educational disengagement, digital exclusion, poor technology management, and increased psychosocial challenge. These barriers can be significantly managed by the faculty while designing the online classes and mode of engagement.

Although teachers' moved to online classes based on HEIs directive, teachers at HEIs have not had enough time to adapt their course contents to online mode, both synchronous and asynchronous. Chaaban and Ellili-Cherif (2017) considered lack of time to look for appropriate online materials that cater to students' level and needs as one of the obstacles teachers encounter. It needs adequate time to find materials that meet the standardized curriculum and assessment implemented in most HEIs (Biancarosa \& Griffiths, 2012; Vrasidas, 2015). Thus, due to the pandemic, teachers shared as many materials as possible and expected students to choose the best materials for themselves, which caused many challenges for students. Amita (2020) stated that learners encountered difficulties in choosing the best source amongst many sent by their teachers, which affected their academic performance and increased their anxiety and frustration.

It suggests that, given the urgency of continuing education online during the pandemic, faculty support is critical in addressing students' academic and social concerns. For instance, a faculty need to maintain effective interaction with their students, give them necessary feedback, and provide them with sufficient learning materials that have a meaningful impact on student's academic and social concerns during the pandemic. Therefore, the empirical discussion furthers the following hypothesis (H1):

- H1: Faculty support significantly affects students' academic and social concerns during online education. 
HEI support also critically influences student experiences in online learning. Recent research established the role of HEI support in student's academic success and wellbeing in general (e.g., technical training and support, counseling support, financial support, communication support, etc.). In their study, Fernandez and Shaw (2020) emphasized the role of effective communication to gain the trust and commitment of faculty, staff, and students. Altamirano and Collazo (2020) cited an example wherein the leaders at Urban Diverse College communicated with staff by weekly emails that contain heartfelt motivational messages and information on developments concerning the community at large. In a national survey, Active Minds (2020) reported that many students expressed that a lack of regular and caring communication from their institutions was a primary stressor during COVID-19. Students expect communications from their HEIs, and checking if have accessibility issue or staying focused during online classes. Besides, HEIs should share meaningful and heartful messages with students. HEIs should also provide support services to facilitate student's success and wellbeing during online learning. Some students may lack the skills or have trouble using online platforms. Zeeshan et al. (2020) emphasized the importance of technical support from their university administration to motivate students to manage technological stresses and develop full readiness for online learning.

Sarker et al. (2019), in their study in a private university in Bangladesh, stated that to obtain optimum benefit from e-learning technologies, HEIs must ensure quality content distribution through user-friendly systems and enhanced asynchronous interaction between the lecturers and students. For instance, HEIs should provide training for both lecturers and students to cope with the new learning environment during the pandemic. HEIs were rated differently in their approach to academic support to faculty and students in the previous empirical literature. Abu Shekhadim et al. (2020) based on a study in Palestine, concluded that HEIs provided moderate support; they did not train students to use e-learning, neither no guidelines disseminated to students on how to use the virtual platforms. Similarly, Draissi and Yong (2020) found that the support provided to students in Moroccan HEIs was insufficient due to the lack of infrastructure needed to implement online education successfully. These empirical findings support WorldBank's (2020) observation that most students had difficulties accessing online learning due to the lack of support from the HEIs. Furthermore, lack of support aggravates student concerns, and simultaneously students lose their interest in attending classes online. Yilmaz et al. (2020) emphasized that many students do not know what to do in the online learning process and need external support; otherwise, their motivation decreases and affects their academic performance.

From the empirical literature on HEI's relevance to students' learning experience, academic and social concerns, the second hypothesis, $\mathrm{H} 2$, is proposed.

- H2: HEI support significantly affects students' academic and social concerns during online education.

Availability of resources is another factor that facilitates the success of online education. Previous research has shown that one of the main challenges for implementing 
a virtual mode of learning is an internet connection which has proven to be a significant issue for students, especially those located in remote areas. Poor internet connection is considered the main challenge for online education during the pandemic in many studies worldwide (e.g., Baticulon et al., 2020; Kamarianos et al., 2020; Means \& Neisler, 2020; Sahu, 2020). A study conducted in China found that network coverage in remote areas is insufficient. Learners in mountainous areas had to walk for hours to find places with stable network signals (Huang et al., 2020).

Similarly, in Egypt, Mahdy (2020) found that learners suffered from poor internet connectivity during the lockdown, which affected the quality of their learning. In Morocco, students encountered several issues during online education due to network capacity and lack of internet access in remote and rural areas. The government addressed it by utilizing television channels to broadcast lectures for HEI students. In Saudi Arabia, limited bandwidth has been a significant issue reported by both teachers and students during the pandemic (Khalil et al., 2020; Alnajjar et al., 2020). Lassoued et al. (2020) investigated the obstacles encountered by 300 students experiencing distance education in four Arab countries during the COVID-19 pandemic (Algerian, Egyptian, Palestinian, and Iraqi). The students stated that the lack of resources needed during online education, namely internet connection, was a significant challenge. In contrast, a study conducted in the UAE (Almuraqab, 2020) found that $74.5 \%$ of respondents had good internet access and appropriate devices for online learning.

Although we focus on infrastructure at HEI, resources available with students, teachers and HEI are also significant determinants of the effectiveness of distance online learning. In Oman, the government has initiated a strategy to provide laptops to all students in HEIs, which is an excellent gesture to ensure the availability of adequate infrastructure during online classes. For instance, in the Mckinsey \& Company report in the USA, Kim et al. (2020) reported that only $11 \%$ of the participants reported having all the necessary equipment for remote learning. Having necessary devices like laptops is an essential requirement for successful online learning. However, many studies indicate that students rely more on their smartphones during online education, which might not be compatible with many online platforms and programs. For example, Mahdy (2020) found that the most used devices by students in 86 countries were smartphones. Also, lack of devices or limited access due to gadget sharing were encountered by medical students in the Philippines (Baticulon et al., 2020) and Pakistan (Abbasi et al., 2020). In addition, during the pandemic, many students have difficulties accessing online education due to the lack of basic digital skills (Lassoued et al., 2020; World Bank, 2020). It caused students to lose interest in attending classes online, affecting their academic achievement (Arënliu \& Bërxulli, 2020; Quacquarelli Symonds, 2020). Shetty et al. (2020) reported many concerns facing students like lack of face-to-face interactions, lack of socialization, distraction by social media, and technology-related issues. They rated their concern about health, hygiene measures, and the feeling of loneliness as the significant reasons for their social concerns. Among the social concerns, students worried about their health and lack of social interaction leading to a lonely life. These observations support Guangul et al. (2020), Fernandez and Shaw (2020), Khalil et al. (2020), and Alnajjar et al. (2020). Reassuring students and parents with targeted communication 
should be vital in the institutional response (Daniel, 2020) to address the student concerns. Daniel (2020) further explained that teachers and counselors might be better than parents at assuaging students' anxieties in deprived situations. HEI should maintain continuous interaction with the students, using synchronous and asynchronous teaching and learning modes. Almuraqab (2020) considered the resources to support teaching and learning an essential requirement to ease students' concerns. (See Fig. 1)

Son et al. (2020) conducted interview surveys with 195 students at a large public university in the United States to understand the effects of the pandemic on their mental health and wellbeing. The majority of the participants indicated increased stress and anxiety due to the COVID-19 outbreak. They fear and worry about their health and loved ones, difficulty concentrating, disruptions to sleeping patterns, decreased social interactions due to social distancing and increased concerns on academic performance. Therefore, the third hypothesis is proposed:

- H3: Resource availability significantly affects students' academic and social concerns during online education.

\section{Research methodology}

\subsection{Data collection method}

A quantitative survey method using a structured questionnaire is adopted for data collection. It is considered as an efficient way of collecting data from many respondents in geographically spread areas within a short time (Campbell et al., 2004). The researchers designed the questionnaire; some items of the questionnaire were developed from the literature review and previous studies (e.g., Quacquarelli Symonds, 2020; Almuraqab, 2020; Abu Shekhadim et al., 2020), while others were based on the researchers' experience and intuitiveness during the

\section{Conceptual framework}

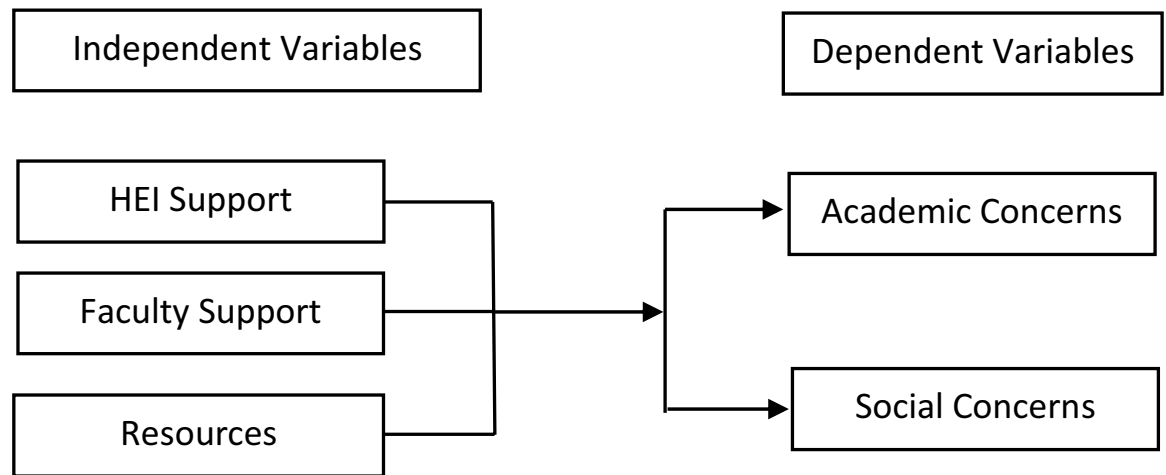

Fig. 1 Conceptual framework 
COVID-19 pandemic. The questionnaire included different parts. Part one consisted of demographic information of the participants such as gender, specialization, year of study, institution type (private or government), location of the HEI, type of internet connection they use (wi-fi or data mobile), and laptop ownership., and tools used for online learning (e.g., laptop, smartphone, or others). Part two consisted of student perceptions of the support provided by HEIs (5 items) and the support provided by faculty (4 items) during Spring 2020. They expressed their perceptions on a five-point Likert scale: "very effective $=5$ ", "effective $=4 "$, "neutral =3", "ineffective =2", and "very ineffective $=1$ ". Part three consisted of student concerns during online education. They have expressed their concern in 7 items. Part four consisted of resources availability needed for online education (6 items). In parts three and four, students have expressed their opinions on a fivepoint Likert scale: "strongly agree =5", "agree =4", "neutral=3", "disagree =2", "strongly disagree $=1$ ". The questionnaire also had open-ended questions that asked students what they appreciated about their lecturers and institutions and the kind of challenges they encountered during online education in the spring semester.

The internal consistency reliability of the questionnaire items was checked through the application of Cronbach's alpha tests of inter-reliability correlations. Table 1 shows Cronbach's Alpha which shows that our questionnaire is reliable given that all the items are above the minimum threshold of 0.7 .

To verify the validity and practicality of the questionnaire (Oppenheim, 2000), it was piloted with a group of students. In addition, to check the content validity, which referred to reviewing the questionnaire items by experts in the field to examine its readability, clarity, and comprehensiveness (Sangoseni et al., 2013), the questionnaire was reviewed by experts in the field, and their suggestions incorporated. The ethical considerations were adhered to by obtaining permission from institutions. Also, a research ethics form was completed and approved. The researchers obtained participants' informed consent before they participated in the online questionnaire, and they were assured that they could withdraw from the study at any time.

The questionnaire was plotted online from June 20 to July 26, 2020. The questionnaire was prepared in Arabic and English so students could adequately express themselves. The questionnaire link using 'Google forms' shared with the Ministry of Higher Education, and they provided full support for this study and communicated with all HEIs in Oman. They shared the link with their students through email and WhatsApp. The responses covered all regions in the Sultanate of Oman.

Table 1 Cronbach's Alpha of the Questionnaire's Sections

\begin{tabular}{llc}
\hline & Number of items & Cronbach's alpha \\
\hline Support provided by the HEI for online education & 5 items & 0.825 \\
Support provided by faculty members during online education & 4 items & 0.835 \\
Resources available for online education & 6 items & .885 \\
Student concerns during online education & 7 items & 0.641 \\
\hline
\end{tabular}


As per the most recent data received from the Education Council in the Sultanate of Oman, there are 127,962 students cumulatively enrolled in HEIs in Oman. In this study, we had 11,141 respondents, a response rate of $9 \%$. This rate is sufficient as it aligns with the generalized scientific guideline for sample size decisions proposed by Krejcie and Morgan (1970). Krejcie and Morgan (1970) noted that as the population increases, the proportion of the population required in the sample size is reduced or even becomes static after reaching a specific limit. However, if the population size is small, then the whole population may be required as the sample (e.g., less than 30) (p. 610). For this study, the suitability of data checked using Kaiser-Meyer-Olkin (KMO) and the Bartlett test. Here the KMO measure is greater than 0.6 (0.938), and the Bartlett test is statistically significant (0.000), so the data is deemed valid for use in this research (Bartlett, 1954; Kaiser, 1974).

\section{Analysis}

Data are coded using Microsoft Excel and performed statistical analysis using Microsoft Excel and SPSS version 22. While reporting descriptive data, the study utilized percentage, mean (M) and standard deviation (SD). Hypothesis testing used the $p$-value, as recommended by Tabachnick and Fidell (2007). The study employed regression analysis and factor loading to explore the underlying relationships and the associations between the dependent and independent variables. Cronbach's alpha score confirmed the internal consistency of the questionnaire.

\section{Results}

This section consists of results related to the main findings: demographic information of the participants, student perceptions of the support provided by HEIs, the support provided by faculty, resources' availability during online education, and student concerns during online education.

\subsection{Demographic information of the participants}

The demographic profile of participants is described in terms of gender, specialization, year of study, and location of the HEIs they attend. Female participants are more than double that of male. Out of the 11,114 students who participated in this study, 7,590 are female (67.9\%), and 3,591 are male (32.1\%). Concerning student's specialization, 3,235 of them belongs to Engineering (28.9\%), 2,769 in Business (24.8\%), 1,918 in Computer Science/ IT (17.2\%), and 1,413 in Nursing (12.6\%). We have fewer respondents from other specializations: Applied Sciences (594), Education (244), Pharmacy (152), Language (101), Islamic Study (97), and Medicine (34). We also have 624 students from other specializations. All our participants are undergraduate students: 2,132 (19.1\%) are still in the foundation 
program, 2,302 (20\%) are in the first year of study, 2,743 (20.6\%) respondents are in the second year of study (24.5\%), 2,074 (18.5\%) in the third year of study, $1,776(15.9 \%)$ in the fourth year of study, and 87 students in other years of their studies. Their age ranged between 18 to 23 years old. Most of our respondents belong to government HEIs $(N=9108,81 \%)$. Furthermore, our participants are studying in HEIs located in different regions in Oman. 35.7\% of participants belong to Muscat $(N=3997)$, as most HEIs locates there. 60.4\% HEIs moved online towards the end of the semester, while $28.7 \%$ and $10.9 \%$ moved online in the middle and at the beginning of the semester, respectively.

At the time of the data collection, less than half of our participants have their laptop $(N=5,140,46 \%)$, while 4,046 share the same laptop with other people in the same house (36.2\%), and 1,995 do not have a laptop at all (17.8\%). Many of our participants have used their mobile data $(N=4,751,42.5 \%)$ for internet connection, while only 2,717 (24.3\%) have used wi-fi at home, and 3,713 (33.2\%) have used both wi-fi and mobile data.

\subsection{Descriptive analysis of the data}

Table 2 presents the descriptive data. Students rated their perceptions with the support provided by the HEIs (3.45) more than the faculty support (3.02). Resource availability such as internet connection, having a suitable place for online studying, and having the required equipment to study online are rated moderate (3.13).

Students' social concerns due to anxiety, worries, and loneliness averaged (4.08). The pandemic and the subsequent lockdown forced students to change their academic routines completely, move online and socially distant. Interestingly, students' academic concerns averaged 4.25. Among the students' academic concerns, whether they will complete the academic semester, the workload during online education, and whether they will graduate on time were major academic concerns. Their average score significantly reflected both academic concerns and social concerns.

An interesting observation based on the correlation, shown in Table 3 , there is a significant relationship between academic concerns and social concerns $(r=0.479, p<0.001)$.

\subsection{Regression analysis}

The results $(f$-statistic $=1047.376, p<0.001)$ explains that $23.3 \%$ of the variability in student's academic concerns (adjusted $\mathrm{R}^{2}=27.5$ ) can be explained by HEI support, faculty support and resource availability. The $\mathrm{R}^{2}$ value is deemed accepted if greater than 0.1 and was deemed adequate for our study (Falk \& Miller, 1992; Van Tonder \& Petzer, 2018). Table 4 gives information about the regression coefficients for the predictor variables entered into the model. HEI support, faculty support, resource availability, and social concerns were significant predictors. Specifically, for the dependent variable (student social concern) an $\mathrm{R}^{2}$ value equal to 0.234 was obtained, which declares that the independent variables (HEI support, faculty support, resources, and 


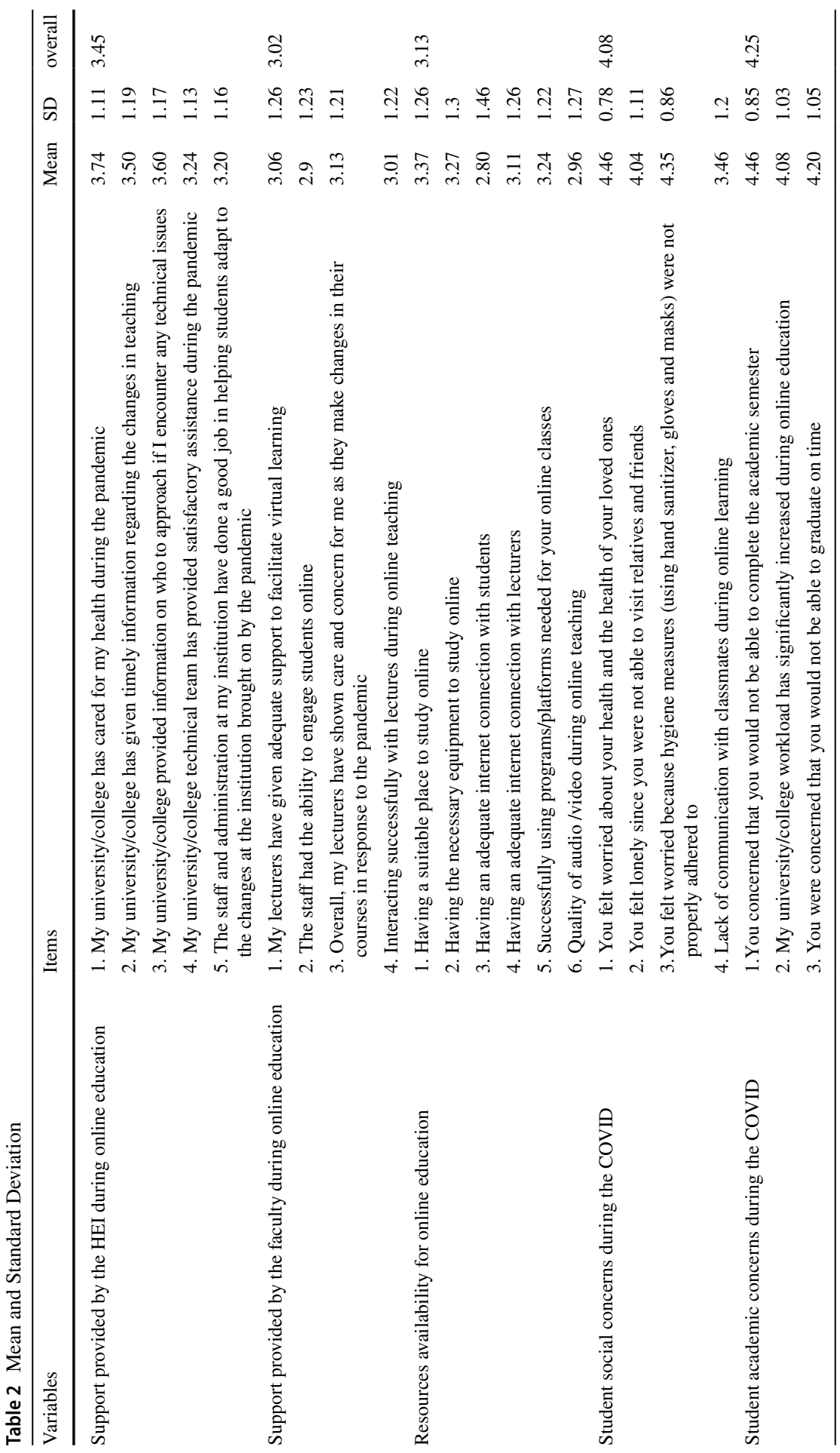


Table 3 Correlation Between Variables Selected

\begin{tabular}{lllll}
\hline Variables & Faculty support & Resources & Social concerns & Academic concerns \\
\hline HEI Support & $.764^{* *}$ & $.451^{* *}$ & $.123^{* *}$ & $.139^{* *}$ \\
Faculty support & & $.608^{* *}$ & $.115^{* *}$ & $.186^{* *}$ \\
Resources & & $.147^{* *}$ & $.274^{* *}$ \\
Social concerns & & & $.479^{* *}$ \\
\hline
\end{tabular}

*Significant at 0.05 level; **significant at 0.01 level

academic concerns) explained this dependent variable at 27.5\%. (See Fig. 2).Similarly, variables that were found significantly correlated with the dependent variable, student social concerns, were entered as predictors into a multiple regression using the standard method. A significant model emerged: $F(4,11,176)=851.781, p<0.001$. The model explains that $23.4 \%$ of the variance in student's social concerns (adjusted

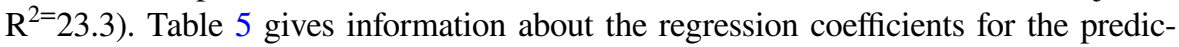
tor variables entered into the model. HEI support, faculty support, resource availability, and social concerns were significant predictors. Specifically, for the dependent variable (student academic concern) an $\mathrm{R}^{2}$ value equal to 0.275 was obtained, which declares that the independent variables (HEI support, faculty support, resources, and social concerns) explained this dependent variable at 23.4\%. (See Fig. 3).

\subsection{Factor analysis}

In order to verify whether the selected variables are significant predictors of the dependent variables, the study utilized factor analysis. The composite reliability, Cronbach's alpha, average variance extracted (AVE), and Variance Inflation Factor

Table 4 Regression Results of (Academic Concern as Dependent Variable)

\begin{tabular}{|c|c|c|c|c|c|c|c|}
\hline $\mathrm{H}_{\mathrm{i}}$ & $\begin{array}{l}\text { Independent } \\
\text { Variables }\end{array}$ & $\begin{array}{l}\text { Dependent } \\
\text { variable }\end{array}$ & $\begin{array}{l}\text { Unstandardized } \\
\text { CoefficientsB }\end{array}$ & SE M & $\begin{array}{l}\text { standardized } \\
\text { Coefficients } \\
\beta\end{array}$ & $p$-value & Interpretation \\
\hline $\mathrm{H}_{1.1}$ & HEI Support & $\begin{array}{r}\text { academic } \\
\text { concern }\end{array}$ & -.025 & .008 & -.039 & .002 & Not rejected \\
\hline $\mathrm{H}_{1 \cdot 2}$ & Faculty support & $\begin{array}{r}\text { academic } \\
\text { concern }\end{array}$ & .025 & .008 & .044 & .002 & Not rejected \\
\hline \multirow[t]{2}{*}{$\mathrm{H}_{1.3}$} & Resources & $\begin{array}{r}\text { academic } \\
\text { concern }\end{array}$ & .111 & .006 & .199 & .000 & Not rejected \\
\hline & $\mathrm{R}^{2}$ & & .275 & & & & \\
\hline
\end{tabular}

$\mathrm{H}_{1}$ : Our data support the hypothesis that the HEI support (e.g., sharing timely information, technical support, and showing care for students) while taking online classes from home during the COVID-19 pandemic has a significant impact on the students' academic concern

$\mathrm{H}_{2}$ : Our data support the hypothesis that the faculty support (e.g., showing care for students, engaging and interacting with them) while taking online classes from home during the COVID-19 pandemic has a significant impact on the students' academic concern

$\mathrm{H}_{3}$ : Our data support the hypothesis that the availability of the resources (e.g., internet connection, equipment needed for online education, suitable places to study) while taking online classes from home during the COVID-19 pandemic has a significant impact on the students' academic concern 


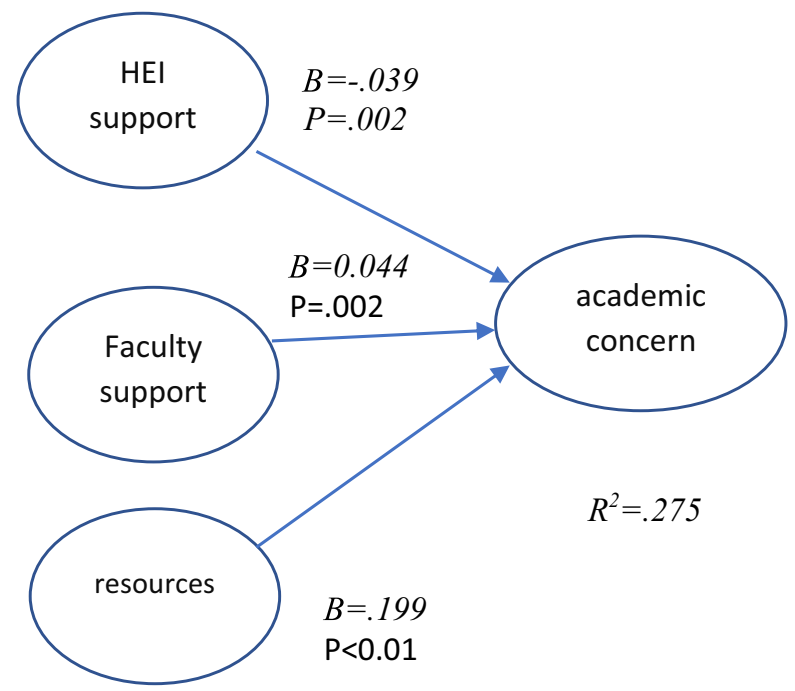

Fig. 2 Regression Results of (Academic Concern as Dependent Variable)

index (VIF) were calculated to test the internal consistency and validity of the model. It is generally known that if the reliability coefficient is above 0.7 , then it is acceptable (Carrasco \& Jover, 2003), which shows that the measures are reliable and internally consistent.

Table 6 shows composite reliability is above 0.70 for all the variables in this study. The model's reliability is considered good if the composite reliability is more than 0.6 and the average variance extracted (AVE) is greater than 0.5 (Srinivasan et al., 2002). This level of AVE or higher indicates that, on average, the construct explains 50 percent or more of the variance of its indicators. Moreover, the AVE in

Table 5 Regression Results of (Social Concern as Dependent Variable)

\begin{tabular}{llllcccc}
\hline $\mathrm{H}_{\mathrm{i}}$ & $\begin{array}{l}\text { Independent } \\
\text { Variables }\end{array}$ & $\begin{array}{l}\text { Dependent } \\
\text { variable }\end{array}$ & $\begin{array}{l}\text { Unstandardized } \\
\text { CoefficientsB }\end{array}$ & $\begin{array}{c}\text { SE M } \\
\text { standardized } \\
\text { Coefficients } \\
\beta\end{array}$ & $p$-value & Interpretation \\
\hline $\mathrm{H}_{2.1}$ & HEI Support & Social concern & .062 & .009 & .089 & .000 & Not rejected \\
$\mathrm{H}_{2.2}$ & Faculty support & Social concern & -.027 & .009 & -.044 & .002 & Not rejected \\
$\mathrm{H}_{2.3}$ & Resources & Social concern & .002 & .006 & .004 & .742 & rejected \\
& & & .234 & & & &
\end{tabular}

$\mathrm{H}_{1}$ : Our data support the hypothesis that the HEI support (e.g., sharing timely information, technical support, and showing care for students) while taking online classes from home during the COVID-19 pandemic has a significant impact on the students' social concern

$\mathrm{H}_{2}$ : Our data support the hypothesis that the faculty support (e.g., showing care for students, engaging, and interacting with them) while taking online classes from home during the COVID-19 pandemic has a significant impact the students' social concern

$\mathrm{H}_{3}$ : Our data do not support the hypothesis that the availability of the resources (e.g., internet connection, equipment needed for online education, suitable places to study) while taking online classes from home during the COVID-19 pandemic has a significant impact on the students' social concern 


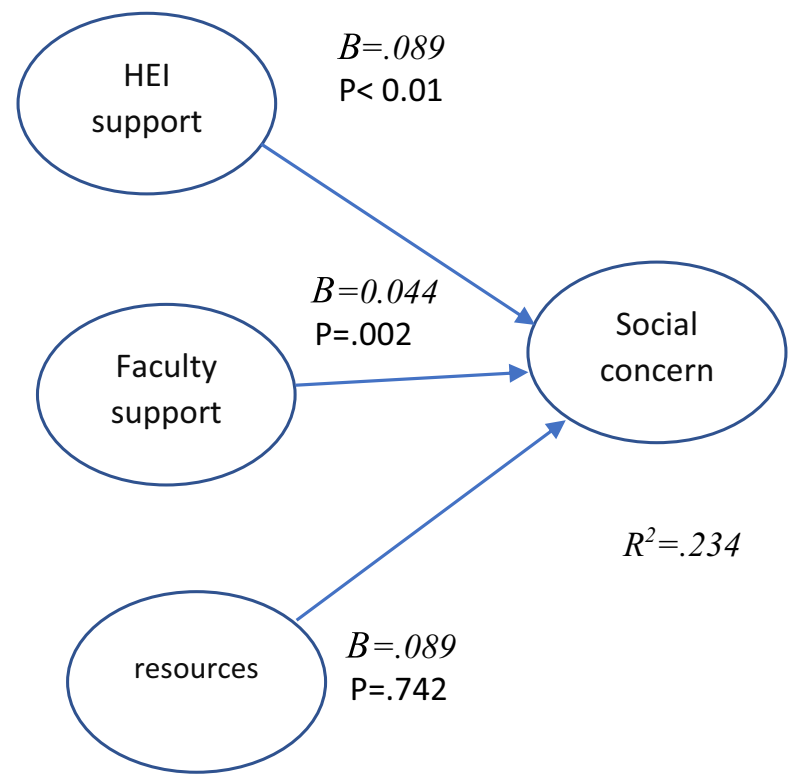

Fig. 3 Regression Results of (Social Concern as Dependent Variable)

this study is above 0.50 , which indicates that the latent variables have a convergence ability that is quite ideal. The Variance Inflation Factor (VIF) is used to measure the degree of multi-collinearity of the independent variable with the other independent variables in a regression model. A value of $\leq 10$ for VIF and 0.10 for the minimum level of tolerance is considered acceptable levels (Rovai et al., 2013).

The changes happening in the DV variable can be explained collectively by the three factors $74.1 \%$ of the time. This means that about $26 \%$ can be explained by other variables not explored in this study. The model's validity is explained here, using the AVE, VIF, Cronbach alpha, Composite Reliability and $\mathrm{R}^{2}$. Based on the factor analysis, HEI support, faculty support and resources are combined as factor

Table 6 Factor Loading

\begin{tabular}{llll}
\hline Indexes & Loading & Acceptable If \\
\cline { 2 - 3 } & $\begin{array}{l}\text { factor 1: HEI support, } \\
\text { faculty support, resources }\end{array}$ & $\begin{array}{l}\text { factor 2: academic } \\
\text { concerns, social } \\
\text { concerns }\end{array}$ & \\
\hline R-squared & .273 & .230 & More than 0.2 \\
Adjusted R-squared & .272 & .230 & More than 0.2 \\
Composite reliability & .860 & .707 & More than 0.7 \\
Cronbach's alpha & .819 & .647 & More than 0.7 \\
Average Variance Extracted (AVE) & .673 & .547 & More than 0.5 \\
Variance Inflation Factor index (VIF) & 2.440 & 1.000 & $0.1<$ VIF $<10$ \\
& $\%$ of Variance 74.154 & $\%$ of Variance 73.963 & \\
\hline
\end{tabular}


I, while social concerns and academic concerns are combined as Factor II. Together they explain $74.4 \%$ of the variance out of total. This means that other factors will explain a $22 \%$ variance. The analysis is done using the rotation method.

\section{Discussion}

While examining the impact of the Covid-19 pandemic on students at HEIs, it is observed that all the empirical literature has univocally concluded that both social and academic concerns significantly influenced student experience in online learning at HEIs. The literature also highlighted the role of HEI support, faculty support, and resources in addressing the social and academic concerns of the students. Three major inferences were drawn based on the analysis. At first, this research supports the previous empirical findings that social concerns and academic concerns significantly affect student learning in online classes during the pandemic. Secondly, this research found that HEI support, faculty support, and resources available are significant predictors of academic concerns. The third important observation is that HEI support and faculty support significantly influence the student's social concerns. All the inferences point out that though the pandemic created social and academic concerns, strategic interventions from the HEI can play a significant role in addressing the concerns. Students feel lonely and are tensed due to the pandemic. However, HEI support, faculty support, and resources can play a major role in reducing social and academic concerns.

As outlined, this research furthers the empirical findings that students' academic and social concerns were significant during the current pandemic. For example, Shetty et al. (2020) considered it due to a lack of face-to-face communication, lack of social interaction, and technology-related issues. They rated their concern about health, hygiene measures, and the feeling of loneliness as the significant reasons for their social concerns. Among the social concerns, students worried about their health and lack of social interaction leading to a lonely life. These observations support Guangul et al. (2020); Fernandez and Shaw (2020); Khalil et al. (2020); Alnajjar et al. (2020); Son et al. (2020). Socialization is a significant part of student experiences before the pandemic. However, the emergency remote teaching, lockdown, and social distancing measures created anxiety and stress among students due to the suspension of face-to-face classes. Empirical research highlighted that students experienced stress, increased anxiety, and feeling less motivated (Almuraqab, 2020; Aristovnik et al., 2020; Duraku \& Hoxha, 2020; Gillis \& Krull, 2020). This research furthers the empirical findings and reports that social concerns significantly influenced their behavior during the pandemic. Four statements were mainly focused on the student's social concerns, and the overall score of the statement was 4.08 , indicating a firm agreement with these statements. This inference is also significant and requires the attention of HEI and faculty.

As the coronavirus (COVID-19) is still around, this is a time of momentous change, and communication with students is more crucial than ever. Therefore, 
HEIs should use all possible means to communicate necessary information to their students. Tyrovolas et al. (2020) in Saudi Arabia reported that students perceived social media (e.g., Facebook and WhatsApp) as a more appropriate tool for communication due to its ease of use and simplicity. Therefore, HEIs should activate their accounts on social media and communicate information to their students. Additionally, the HEIs should communicate with students personally through personalized messaging and orientations as it is known that personal touch is an effective technique for involving students and supporting them. HEIs can also produce videos about health and safety measures or rationale for decisions made and send them to students and their families. In addition, the HEIs should support students to diminish students' concerns by providing them with counseling services. Daniel (2020) explained that counselors might be better than parents at assuaging students' anxieties in deprived situations.

Specifically addressing the academic concerns, this research established that HEI support, faculty support, and resources significantly influence student's academic concerns. Unlike face-to-face teaching, wherein the students and faculty interact daily, online learning created a physical distance. Add to this the social pressures and tensions posed by the pandemic. In order to mitigate students' academic concerns, HEIs strategic interventions are required. For instance, the HEIs have to design appropriate and compelling content and establish an adequate infrastructure for their current faculty to achieve better learning outcomes.

Furthermore, HEIs should provide their faculty with the necessary training to successfully carry out online learning, increase student interaction, and achieve quality in online education. HEIs must encourage synchronous online sessions since they give lecturers more opportunities to interact with their students, respond to their inquiries, and establish peer collaboration, leading to a better understanding of the topics studied (Papadima-Sophocleous \& Loizides, 2016). Teachers should utilize professional development activities to improve their technological and pedagogical competencies. Communities of Practice (COP) are recommended to share common interests or passion in a certain area and regularly meet to exchange ideas and assist each other to develop professionally (Wenger et al., 2002).

The reasons for academic concerns are increased workload (Realyvásquez-Vargas et al., 2020; Aristovnik et al., 2020; Mishra et al., 2020), the volume of assignments (Al-Salman \& Haider, 2021) lack of proper guidance (Ali, 2020; Sullivan et al., 2018). All these factors were significant based on the analysis. For instance, the statement "my university/college workload has significantly increased during online education' is rated as strongly agree, with a mean score of 4.08 by students. This observation supports the empirical research findings and requires the attention of HEI administrators. As students, similar to any other group of people, are also undergoing tremendous pressure due to the pandemic in terms of health and safety concerns and feelings of loneliness, adding more assignments and activities will only negatively impact their studies. This also requires HEIs and faculty to continuously interact with students and address their concerns to feel supported during this pandemic. Blackmon and Major (2012) emphasized that teachers had a substantial impact on students' online education experience, largely through their being accessible during the course and providing needed support to their students. They also 
highlighted that if the students had negative experiences with their teachers due to lack of contact or support, students would be uncomfortable during the online experience, affecting their performance. Therefore, the HEIs need to develop policies and procedures to ensure that teachers provide adequate support for their students during the online teaching mode. This can be done via conducting one-to-one meetings with individuals or groups of students to address their needs or via their efforts to provide opportunities for their students to connect with peers.

The findings revealed that resources such as internet connectivity have also impacted student's academic concerns. Internet connectivity issues hinder student's ability to attend and participate in their course online. Internet connection has been an issue for many years, and the research findings complement numerous previous studies in different parts of the world, not exclusively limited to Oman (Ali, 2020; Amita, 2020; Duraku \& Hoxha, 2020; Huang et al., 2020; Lassoued et al., 2020; Means \& Neisler, 2020). Therefore, Oman needs to enhance its online infrastructure, especially internet connection, speed, and internet prices to benefit from online learning in the future.

\section{Conclusion}

Given that the pandemic is ongoing worldwide and strict measures are still continuously applied, such as lockdown and distance education, the COVID-19 pandemic negatively impacts higher education. The research findings demand interventions and preventive strategies to address the academic and social concerns of students. They need psychosocial and robust counseling services to provide the necessary support to help them overcome this stage. Even though COVID has changed the way universities operate, most importantly, HEIs should exert more effort to care for their students and make sure that their concerns are well managed. This can be achieved by constant communication with them and considering sustainable mental health support as a priority for the university. Purcell and Lumbreras (2021) stated that the pandemic is a period of punctuated equilibrium. The learnings from this period could lead to transformation in the HEI sector towards more significant equity and impact across teaching/learning, research/innovation, community service/engagement, and the staff/students' experience.

Future work should concentrate on students' equal access to DE where student needs and technical profiles are investigated, so necessary policies and interventions can be suggested to provide equal opportunities to all students. In addition, future research should examine the types of interactions among students and teachers during DE and their effectiveness. This is in addition to identifying the best practices to ensure students' wellbeing during DE and maintaining their active engagement with their HEIs, teachers, and peers. In addition, a similar study can be conducted to examine teachers' academic and social concerns, 
Acknowledgements The authors would like to sincerely appreciate the support provided by the Education Council, the Ministry of Higher Education, and the different higher education institutions in Oman. Appreciation is also extended for students for their valuable time and answering the surveys for this research.

Funding No fund was received for this research.

\section{Declaration}

Conflict of interest The authors declare that they have no competing interests.

\section{References}

Abbasi, S., Ayoob, T., Malik, A., \& Memon, S. I. (2020). Perceptions of students regarding E-learning during Covid-19 at a private medical college. Pakistan Journal of Medical Sciences, 36(COVID19-S4).

Active Minds. (2020). "The Impact of COVID-19 on Student Mental Health." COVID-19 Student Survey. https://www.activeminds.org/studentsurvey/.

Adnan, M., \& Anwar, K. (2020). Online Learning amid the COVID-19 Pandemic: Students' Perspectives. Online Submission, 2(1), 45-51.

Almanthari, A., Maulina, S., \& Bruce, S. (2020). Secondary school mathematics teachers' views on e-learning implementation barriers during the Covid-19 pandemic: The case of Indonesia. Eurasia Journal of Mathematics, Science and Technology Education, 16(7).

Ali, W. (2020). Online and remote learning in higher education institutes: A necessity in light of COVID19 pandemic. Higher Education Studies, 10(3), 16-25.

Almuraqab, N. A. S. (2020). Shall universities at the UAE continue distance learning after the Covid-19 pandemic? Revealing students' perspective. International Journal of Advanced Research in Engineering and Technology (IJARET), 11(5).

Alnajjar, H., Asif, U., \& Bano, N. (2020). Faculty Experiences with Emergency Transition to Online Teaching amid COVID-19 Pandemic in a Health Science University. Prensa Medica Argentina, S2, 024. https://doi.org/10.47275/0032-745X-S2-024

Al-Salman, S., \& Haider, A. S. (2021). Jordanian University Students' Views on Emergency Online Learning during COVID-19. Online Learning, 25(1), 286-302.

Altamirano, M. A., \& Collazo, C. E. R. (2020). Leading with Emotional Intelligence: How Leaders of a Diverse-Based Urban College in New York Successfully Respond to the COVID-19 Crisis of 2020. COmmunication is RObust when NAtions Come Together: The Importance of Collaboration during a Global Crisis.

Amita. (2020). E-learning experience of students in higher education institutions during the Covid-19 pandemic: A primary survey. In Raj Pal Singh, Anupama Singh and Rakesh Kumar, COVID-19 Pandemic: A Global Challenge (pp. 115-131), ISBN 978-93-86695-28-4. New Delhi: Aryan Publications.

Arënliu, A., \& Bërxulli, D. (2020). Rapid assessment: Psychological distress among students in Kosovo during the COVID-19 pandemic Retrieved from https:/www.researchgate.net/publication/ 340262171_Rapid_assessment_Psychological_distress_among_students_in_Kosovo_during_the_ COVID_19_pandemic

Aristovnik, A., Keržič, D., Ravšelj, D., Tomaževič, N., \& Umek, L. (2020). Impacts of the COVID-19 pandemic on life of higher education students: A global perspective. Sustainability, 12(20), 8438.

Bartlett, M. S. (1954). A note on the multiplying factors for various $\chi 2$ approximations. Journal of the Royal Statistical Society: Series B (methodological), 16(2), 296-298.

Basilaia, G., \& Kvavadze, D. (2020). Transition to online education in schools during a SARS-CoV-2 coronavirus (COVID-19) pandemic in Georgia. Pedagogical Research, 5(4).

Bates, R., \& Khasawneh, S. (2007). Self-efficacy and college students' perceptions and use of online learning systems. Computers in Human Behavior, 23(1), 175-191.

Baticulon, R. E., Alberto, N. R. I., Baron, M. B. C., Mabulay, R. E. C., Rizada, L. G. T., Sy, J. J., \& Reyes, J. C. B. (2020). Barriers to online learning in the time of COVID-19: A national survey of medical students in the Philippines. medRxiv. 
Biancarosa, G., \& Griffiths, G. G. (2012). Technology tools to support reading in the digital age. The Future of Children, 139-160.

Blackmon, S. J., \& Major, C. (2012). Student experiences in online courses: A Qualitative Research Synthesis. Quarterly Review of Distance Education, 13(2).

Campbell, A., McNamara O., \& Gilroy, P. (2004). "Researching professional development." Practitioner Research and Professional Development in Education, 12-27.

Carrasco, J. L., \& Jover, L. (2003). Assessing individual bioequivalence using the structural equation model. Statistics in medicine, 22, 901-912. [CrossRef] [PubMed]

Chaaban, Y., \& Ellili-Cherif, M. (2017). Technology integration in EFL classrooms: A study of Qatari independent schools. Education and Information Technologies, 22(5), 2433-2454.

Cohen, J. (2017). Maker principles and technologies in teacher education: A national survey. Journal of Technology and Teacher Education, 25(1), 5-30.

Daniel, J. (2020). Education and the COVID-19 pandemic. Prospects, 49, 91-96.

Draissi, Z., \& ZhanYong, Q. (2020). COVID-19 Outbreak Response Plan: Implementing Distance Education in Moroccan Universities. Available at SSRN 3586783.

Drane, C., Vernon, L., \& O'Shea, S. (2020). The impact of 'learning at home'on the educational outcomes of vulnerable children in Australia during the COVID-19 pandemic. Literature Review Prepared by the National Centre for Student Equity in Higher Education. Curtin University, Australia.

Duraku, Z. H., \& Hoxha, N. (2020). The impact of COVID-19, school closure, and social isolation on gifted students' wellbeing and attitudes toward remote (online) learning. Available from https://doi.org/10. 13140/RG.2.2.23967.38567/1.

Falk, R. F., \& Miller, N. B. (1992). A primer for soft modeling. University of Akron Press.

Fernandez, A. A., \& Shaw, G. P. (2020). Academic Leadership in a Time of Crisis: The Coronavirus and COVID-19. Journal of Leadership Studies, 14(1), 39-45.

Ferriman, J. (2013). 5 Reasons Why MOOCs Provide Little Real Value, LearnDash, February 18, available at http://www.learndash.com/5-reasons-why-moocs-provide-little-real-value/, accessed September 19, 2013.

Gillis, A., \& Krull, L. M. (2020). COVID-19 Remote Learning Transition in Spring 2020: Class Structures, Student Perceptions, and Inequality in College Courses. Teaching Sociology, 48(4), 283-299.

Guangul, F. M., Suhail, A. H., Khalit, M. I., \& Khidhir, B. A. (2020). Challenges of remote assessment in higher education in the context of COVID-19: a case study of Middle East College. Educational Assessment, Evaluation and Accountability, 1-17.

Hetsevich, I. (2017). Advantages and Disadvantages of E-Learning Technologies for Students. Joomlalms.

Holmberg, B. (1977). Distance education: A survey and bibliography.

Huang, R. H., Liu, D. J., Tlili, A., Yang, J. F., \& Wang, H. H. (2020). Handbook on facilitating flexible learning during educational disruption: The Chinese experience in maintaining undisrupted learning in COVID-19 Outbreak. Smart Learning Institute of Beijing Normal University.

Kaiser, H. F. (1974). An index of factorial simplicity. Psychometrika, 39(1), 31-36.

Kamarianos, I., Adamopoulou, A., Lambropoulos, H., \& Stamelos, G. (2020). Towards an understanding of university students'response in times of pandemic crisis (COVID-19). European Journal of Education Studies, 7(7).

Khalil, R., Mansour, A. E., Fadda, W. A., Almisnid, K., Aldamegh, M., Al-Nafeesah, A., \& Al-Wutayd, O. (2020). The sudden transition to synchronized online learning during the COVID-19 pandemic in Saudi Arabia: A qualitative study exploring medical students' perspectives. BMC Medical Education, 20(1), $1-10$.

Kim, H., Krishnan, C., Law, J., \& Rounsaville, T. (2020). "COVID-19 and US higher education enrollment: Preparing leaders for fall."

Krejcie, R. V., \& Morgan, D. W. (1970). Determining sample size for research activities. Educational and Psychological Measurement, 30(3), 607-610.

Lassoued, Z., Alhendawi, M., \& Bashitialshaaer, R. (2020). An Exploratory Study of the Obstacles for Achieving Quality in Distance Learning during the COVID-19 Pandemic. Education Sciences, 10(9), 232.

Mahdy, M. A. (2020). "The Impact of COVID-19 Pandemic on the Academic Performance of Veterinary Medical Students."

Means, B., \& Neisler, J. (2020). Suddenly online: a national survey of undergraduates during the COVID-19 pandemic. Digital Promise.

Mishra, L., Gupta, T., \& Shree, A. (2020). Online teaching-learning in higher education during lockdown period of COVID-19 pandemic. International Journal of Educational Research Open, 1, 100012. 
Oppenheim, A. N. (2000). Questionnaire design, interviewing and attitude measurement. Bloomsbury Publishing.

Papadima-Sophocleous, S., \& Loizides, F. (2016). Exploring the benefits and disadvantages of introducing synchronous to asynchronous online technologies to facilitate flexibility in learning. CALL communities and culture-short papers from EUROCALL, 363-368.

Purcell, W. M., \& Lumbreras, J. (2021). Higher education and the COVID-19 pandemic: Navigating disruption using the sustainable development goals. Discover Sustainability, 2(1), 1-16.

Realyvásquez-Vargas, A., Maldonado-Macías, A. A., Arredondo-Soto, K. C., Baez-Lopez, Y., CarrilloGutiérrez, T., \& Hernández-Escobedo, G. (2020). The impact of environmental factors on academic performance of university students taking online classes during the COVID-19 Pandemic in Mexico. Sustainability, 12(21), 9194.

Rovai, A. P., Baker, J. D., \& Ponton, M. K. (2013). Social science research design and statistics: A practitioner's guide to research methods and IBM SPSS. Watertree Press LLC.

Sangoseni, O., Hellman, M., \& Hill, C. (2013). Development and validation of a questionnaire to assess the effect of online learning on behaviors, attitudes, and clinical practices of physical therapists in the United States regarding evidenced-based clinical practice. Internet Journal of Allied Health Sciences and Practice, 11(2), 7.

Sahu, P. (2020). Closure of universities due to Coronavirus Disease 2019 (COVID-19): impact on education and mental health of students and academic staff. Cureus, 12(4).

Sarker, M. F. H., Al Mahmud, R., Islam, M. S., \& Islam, M. K. (2019). Use of e-learning at higher educational institutions in Bangladesh. Journal of Applied Research in Higher Education.

Shekhadim, A., Awad, E. A., \& Khalil, K. A. (2020). The effectiveness of e-learning in light of the spread of the Corona virus from the viewpoint of teachers at the University Palestine Tech (Khadouri). Arab Journal for Scientific Publishing (AJSP), 21, 365-389. https://staff.najah.edu/media/published_research/2020/06/20/

Shetty, S., Shilpa, C., Dey, D., \& Kavya, S. (2020). Academic crisis during COVID-19: Online classes, a panacea for imminent doctors, Indian Journal of Otolaryngoly and Head Neck Surgery, pp.1-5.

Son, C., Hegde, S., Smith, A., Wang, X., \& Sasangohar, F. (2020). Effects of COVID-19 on college students' mental health in the United States: Interview survey study. Journal of Medical Internet Research, 22(9), e21279.

Srinivasan, R., Lilien, G. L., \& Rangaswamy, A. (2002). Technological opportunism and radical technology adoption: An application to e-business. Journal of Marketing, 66, 47-60.

Sullivan, R., Neu, V., \& Yang, F. (2018). Faculty development to promote effective instructional technology integration: A qualitative examination of reflections in an online community. Online Learning, 22(4), 341-359.

Symonds, Q. (2020). The impact of the coronavirus on global higher education. Retrieved from https://www. qs.com/

Tabachnick, B. G., \& Fidell, L. S. (2007). Experimental designs using ANOVA (p. 724). Belmont, CA: Thomson/Brooks/Cole.

Tyrovolas, S., El Bcheraoui, C., Alghnam, S. A., Alhabib, K. F., Almadi, M. A. H., Al-Raddadi, R. M., \& Mokdad, A. H. (2020). The burden of disease in Saudi Arabia 1990-2017: Results from the Global Burden of Disease Study 2017. The Lancet Planetary Health, 4(5), e195-e208.

UNESCO IESALC. (2020). COVID-19 and higher education: Today and tomorrow. Impact analysis, policy responses and recommendations. Retrieved from http://www.iesalc.unesco.org/en/wp-content/uploads/ 2020/04/COVID-19-EN090420-2.pdf

Van Tonder, E., \& Petzer, D. J. (2018). The interrelationships between relationship marketing constructs and customer engagement dimensions. The Service Industries Journal, 38(13-14), 948-973.

Vrasidas, C. (2015). The rhetoric of reform and teachers' use of ICT. British Journal of Educational Technology, 46(2), 370-380.

Wenger, E., McDermott, R. A., \& Snyder, W. (2002). Cultivating communities of practice: A guide to managing knowledge. Harvard Business Press.

World Bank. (2020). The COVID-19 Crisis Response: Supporting Tertiary Education for Continuity, Adaptation, and Innovation.

Yilmaz, R., Yilmaz, F. G. K., \& Keser, H. (2020). Vertical versus shared e-leadership approach in online project-based learning: a comparison of self-regulated learning skills, motivation and group collaboration processes. Journal of Computing in Higher Education, 1-27.

Zeeshan, M., Chaudhry, A. G., \& Khan, S. E. (2020). Pandemic preparedness and techno stress among faculty of DAIs in Covid-19. Sir Syed Journal of Education \& Social Research (SJESR), 3, 383-396. 
Zhou, P., Yang, X. L., Wang, X. G., Hu, B., Zhang, L., Zhang, W., \& Shi, Z. L. (2020). A pneumonia outbreak associated with a new coronavirus of probable bat origin. Nature, 579(7798), 270-273.

Publisher's Note Springer Nature remains neutral with regard to jurisdictional claims in published maps and institutional affiliations. 